of Commerce and congressmen representing areas of the United States which are suffering hardest from the current recession.

Furthermore, according to a report published last month by the Defense Science Board (DSB) on the state of the nation's research universities and their ability to absorb increased military research funds, many universities which had rejected close involvement with the Pentagon in the late 1960 s and early 1970 s are now experiencing a change of heart.

The DSB study has been used by the Department of Defense to justify the major increase in university research funding which it is asking Congress to support. In his budget request last month, President Reagan proposed a 30.5 per cent increase in university basic research funded by the Army, to a total of $\$ 92.1$ million; a 36.9 per cent increase in such research funded by the Air Force, to reach $\$ 89.7$ million; and a 17.2 per cent increase in Navy funding. Basic research supported by the Defense Advanced Research Projects Agency would rise to $\$ 8.4$ million, a 21.7 per cent increase. Many of the extra funds would go explicitly to raise the level of effort in the mathematical sciences, electronics, chemistry and engineering conversion.

The details of the Defense Department's budget request reflect some of the science board's conclusions and some of the universities' concern. In response to complaints about the declining state of the universities' research facilities, the department has announced its intention to allocate $\$ 150$ million over a five-year period to improving research instrumentation. Each of the three major services will put aside $\$ 10$ million a year for this purpose.

The department is also attempting to overcome the increasing difficulty of universities in retaining top graduates in fields such as engineering by setting up a new graduate fellowship programme. Stipends will be $\$ 12,000$ a year - about 50 per cent higher than comparable awards made by the National Science Foundation - and the services will, in addition, provide affiliated universities with $\$ 8,000$ a year to cover tuition and fees.

The initial plans are to award about 125 graduate fellowships in the fiscal year 1983 . which starts on 1 October 1982, costing the Department of Defense about $\$ 2.5$ million. Dr Jack Crowley of the Association of American Universities has said that the association warmly supports both the proposed funding for research facilities and the new fellowship programme.

If Congress does grant the extra funds there is unlikely to be any shortage of applications for the additional grants. With support for basic research from other agencies by falling in real terms and with industry unlikely to be able to make up much of the shortfall, the universities are looking to the Department of Defense as the only significant alternative source of support.

David Dickson
Oceanographic research

\section{In the black}

At a time when many groups are hard pressed to support large projects, a team from the UK Institute of Oceanographic Sciences (IOS) has just returned from a successful six-month cruise on which it earned more than $£ 250,000$ in foreign currency. IOS, now run by the Natural Environment Research Council, has been able to share the cost of its unique side-scan sonar project GLORIA (Geological LongRange Inclined ASDIC) by combining its interests with those of several research groups abroad. With the ability to scan a swathe of the ocean floor almost ten times wider than conventional deep-tow sonars, the equipment is quicker and cheaper than other survey techniques, and many groups overseas are apparently eager to use it.

Research on this multi-project charter the first long voyage to use GLORIA was strongly oriented towards commercial applications, principally oil exploration and radioactive waste disposal. The UK Department of Energy commissioned the first part of the voyage, with an extensive survey off Newfoundland aimed at completing a reconstruction of the North Atlantic during the Cretaceous to help

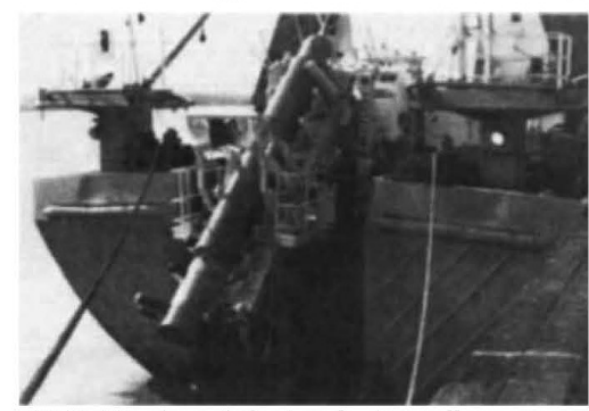

GLORIA aboard the trawler Farnella

assess the oil potential of Britain's continental shelf. The other British project, from the Department of the Environment, was an investigation of the possible disposal of high-level radioactive waste under the sea bed. Searching for specific sites is not the primary objective at present; the department is more interested in using GLORIA's ability to distinguish fine textural changes in the ocean floor to study the varying types of sea-bed environment.

One of the most exciting finds came from an area known as the Amazon Cone off the Brazilian coast. This is a huge pile of sediments washed out by the Amazon into the Atlantic, and is thought to be a potentially important source of oil. Submarine current meanders were for the first time observed to cut into the cone, giving new clues about processes of sediment deposition that may be relevant to the formation of oil-bearing structures. There has been great interest in this finding from petroleum geologists and from the Brazilian oil company Petrobras, which paid for this leg of the cruise jointly with the Lamont-Doherty Geological Observatory of New York's Columbia University.

During the last leg of the voyage, on the way home from Miami, GLORIA was tested as a means of detecting deposits of manganese nodules, which at present can be located only by trial and error sampling. There seems to be a chance that GLORIA's sensitivity to slight variations in the reflectivity and roughness of the bed may offer a more direct means of location. United States scientists are said to have been impressed with the equipment.

David Millar

\section{Soviet shake up}

A regional earthquake monitoring centre has been opened in Dushanbe, in the Soviet republic of Tadjikstan, as a first step towards a seismic early warning system for the whole Soviet Union. Tadjikstan suffers several thousand earth tremors a year, and seismic activity is also very high in the neighbouring republics of Turkmenia, Uzbekkstan, Kirghizia and Kazakhstan.

The new centre will combine the resources of existing seismological centres of the Academies of Sciences of the various republics in the area, including a seismic testing ground covering 30,000 square kilometres in the northern Tien-Shan. The facilities of this site include wells 3,000 kilometres deep for studying subterranean waters - in particular the radon content of such waters which has been observed to increase shortly before a tremor. Field stations at the site also monitor the Earth's magnetic field and telluric currents, while microdisplacements of individual crustal blocks are measured with lasers. Biological teams monitor the behaviour of snakes, ants and other fauna said to behave abnormally during the build-up to an earthquake.

In 1980-81 Soviet seismologists say they successfully predicted the occurrence of 13 earthquakes, including force 4-5 tremors in Dushanbe. The seismologists seem very open-minded to any suggestions of possible early-warning signals. Recent investigations have included the relationship of the amount of mercury vapour emitted from the Earth's crust, or present in subterranean well water, and an assessment of local folk lore which has it that a seismic shock is frequently preceded by overcast skies and dust-storms.

The heart of the Dushanbe centre will be a computerized seismological data bank, linking existing centres, to be augmented by links to new mobile seismic monitoring stations scheduled to go into production in the near future.

Vera Rich 